\title{
Silencing Prion Protein in HT29 Human Colorectal Cancer Cells Enhances Anticancer Response to Fucoidan
}

\author{
CHUL WON YUN ${ }^{1,2^{*}}$, SEUNGPIL YUN ${ }^{3 *}$, JUN HEE LEE ${ }^{3}$, YONG-SEOK HAN ${ }^{1,2}$, \\ YEO MIN YOON ${ }^{1,2}$, DANIEL AN $^{3}$ and SANG HUN LEE ${ }^{1,2}$
${ }^{1}$ Medical Science Research Institute, Soonchunhyang University, Seoul Hospital, Seoul, Republic of Korea;
${ }^{2}$ Department of Medical Bioscience, Soonchunhyang University, Asan, Republic of Korea;
${ }^{3}$ Neuroregeneration and Stem Cell Programs, Institute for Cell Engineering, Department of Neurology,
The Johns Hopkins University School of Medicine, Baltimore, MD, U.S.A.

\begin{abstract}
Background: The putative functions of the cellular prion protein $\left(\mathrm{PrP}^{c}\right)$ are believed to be associated with cell signaling, differentiation, survival, and cancer progression. With respect to cancer development and progression, elevations and mutations of $\operatorname{PrP}^{c}$ expression have been shown to increase the risk for malignancy and metastasis in breast and colorectal cancer. Since both natural supplements and direct regulation of $\operatorname{PrP}^{c}$ expression contribute to inhibition of cancer progression and growth, we hypothesized that knockdown of $\operatorname{PrP}^{c}$ could lead to an enhanced synergic effect on the inhibition of cancer growth by fucoidan. Materials and Methods: $\operatorname{PrP}^{c}$ expression was suppressed in HT29 human colon cancer cells by utilizing small-interfering RNA (si-PRNP), and cells were subsequently used to study the antiproliferative and anticancer effects of fucoidan treatment of HT29 human colon cancer cells. Results: Fucoidan treatment significantly inhibited growth and reduced cyclin and cyclin-dependent kinase (CDK) expression in HT29 colon cancer cells. Furthermore, silencing $\operatorname{PrP}^{c}$ expression with si-PRNP amplified the fucoidan-induced changes in cell proliferation, apoptosis, and migration. Intraperitoneal injection of si-PRNP with fucoidan reduced proliferation and tumor volume in Balb/c nude mice. This enhanced antitumor efficacy was associated with decreased angiogenesis. Conclusion: Combination of fucoidan with silencing of $\mathrm{PrP}^{c}$ has a synergic effect on the inhibition of HT29 colon cancer cell growth.
\end{abstract}

This article is freely accessible online.

*These Authors contributed equally to this work.

Correspondence to: Sang Hun Lee, Medical Science Research Institute, Soonchunhyang University, Seoul Hospital, 59, Daesagwanro (657 Hannam-dong), Yongsan-gu, Seoul, 140-887, Republic of Korea. Tel: +82 27099029, e-mail: jhlee0407@sch.ac.kr

Key Words: Fucoidan, proliferation, migration, cellular prion protein.
Furthermore, we provide evidence for the therapeutic application of $\mathrm{PrP}^{c}$ silencing with other anticancer drugs for cancer.

Developing natural products and dietary supplements has proven to be a promising strategy for the cancer therapy and prevention. Among them, fucoidan, which is isolated from brown seaweed such as Cladosiphon okamuranus and Fucus evanescens $(1,2)$, is structurally similar to heparin, with a substantial percentage of L-fucose $(3,4)$. Recent studies have shown its various effects on biological activities such as antiinflammatory, anti-coagulant (5), anti-HIV, and anticancer (6-9) activities. With respect to cancer therapy, fucoidan appears to be highly efficient in treating certain types of cancer, including breast, prostate and lung, as well as leukemia (10-12). Furthermore, fucoidan can also play a crucial role in inhibiting induced cancer signaling molecules, such as vascular endothelial growth factor (VEGF) $(13,14)$. Although these results support the potential development of fucoidan as an anticancer drug, there is little information on the anticancer effect of fucoidan on colorectal cancer (CRC).

$\mathrm{CRC}$ is the second most commonly diagnosed cancer among females and third among males worldwide. It also contributes significantly to cancer-related deaths, despite continuous progress in developing diagnostic and therapeutic methods (15). It is thought that CRC may be caused by a combination of both genetic susceptibilities and Iifestyle factors such as a meat-rich diet (16). Although the discovery of factors that cause CRC give new insights into the growth and metastasis of CRC, there is still little information on the etiology of most CRC, therapeutic agents, and anti-CRC targeting molecules. However, cellular prion protein $\left(\mathrm{PrP}^{\mathrm{c}}\right)$ expression has been identified as a risk or susceptibility factor for developing CRC (17). In essence, $\operatorname{PrP}^{\mathrm{c}}$ is a highly conserved cell-surface glycoprotein that has been identified in all vertebrates, with the same protein sequence as the prion proteins that cause 
scrapies in sheep, bovine spongiform encephalopathy in cattle, and kuru in human beings $(18,19)$. In addition to its functions in prion diseases, $\operatorname{PrP}^{\mathrm{c}}$ has been associated with roles in several human tumors, including gastric, breast, prostate, and colorectal cancer, and glioblastoma (20). However, there is little evidence from research trials to show that the synergic effect of silencing $\operatorname{PrP}^{\mathrm{c}}$ with application of fucoidan can reduce the growth of CRC cells, and this necessitates further studies to understand how fucoidan affects the inhibition of CRC. Thus, the purpose of our study was to understand the role of fucoidan in CRC growth, and how $\operatorname{PrP}^{\mathrm{c}}$ interacts with fucoidan to produce synergic anticancer effects. To address this, HT29 human colorectal cancer cells were treated or transfected with fucoidan or small-interfering RNA against $\operatorname{PrP}^{\mathrm{c}}$ (siPRNP). The growth and volume of treated cancer cells were evaluated by assessing cell-cycle regulatory proteins, cell death-related proteins, and cell motility. Western blot, flow cytometry, and quantitative assessments, along with immunohistochemistry for proliferating cell nuclear antigen (PCNA), caspase 3, VEGF, and human cluster of differentiation 31 (hCD31), and the intraperitoneal injection of cancer cells were used to study the cell-cycle of HT29 human CRC cells.

\section{Materials and Methods}

Preparation of fucoidan. Fuciodan extracted from the seaweed Fucus vesiculosus was obtained from Sigma (St. Louis, MO, USA). Fucoidan powder was dissolved in phosphate-buffered saline (PBS), filtersterilized through a $0.45-\mu \mathrm{m}$ pore filter (Sartorius Biotech $\mathrm{GmbH}$, Gottingen, Germany), and stored as fucoidan extract $(20 \mathrm{mg} / \mathrm{ml})$ at $4^{\circ} \mathrm{C}$ until use.

Cells and cell culture. The human colon cancer cell line (HT29) was obtained from the American Type Culture Collection (Manassas, VA, USA). The cells were maintained in Dulbecco's modified Eagle's medium (4.5 g/l glucose) supplemented with $10 \%$ fetal calf serum, L-glutamine, and antibiotics (Biological Industries, BeitHaemek, Israel) at $37^{\circ} \mathrm{C}$ with $5 \% \mathrm{CO}_{2}$ in a humidified incubator.

Cell viability assay. Exponentially growing colon cancer cells were subconfluently incubated in 96-well plates with fucoidan $(0-200 \mu \mathrm{g} / \mathrm{ml})$ for various periods of time $(0-48 \mathrm{~h})$. Cell viability was determined using a modification of the 3-(4,5-dimethylthiazol-2-yl)2,5-diphenyltetra-zolium bromide (MTT) assay, which is based on the conversion of the tetrazolium salt 3-(4,5-dimethylthiazol-2-yl)5-(3-carboxymethoxy-phenyl)-2-(4-sulfophenyl)-2-tetrazolium to formazan by mitochondrial dehydrogenase. Formazan was quantified by measuring absorbance at $570 \mathrm{~nm}$, using a microplate reader (Tecan, Männedorf, Switzerland).

Inhibition of $\mathrm{PrP}^{c}$ expression by small RNA interference. HT29 $\left(2.5 \times 10^{5}\right)$ cells were seeded in $60 \mathrm{~mm}$ dishes and transfected with siRNA in serum-free Opti-MEM (Gibco BRL) using Lipofectamine 2000 following the manufacturer's instructions (Thermo Fisher
Scientific). At $48 \mathrm{~h}$ after transfection, the total protein extracted was determined by western blot analysis. The siRNA used to target PRNP and a scrambled sequence was synthesized by Bioneer (Daejeon, Korea).

Wound-healing migration assay. HT29 cells were seeded onto $60 \mathrm{~mm}$ cell culture plate and cultured at $90 \%$ confluence in $4 \mathrm{ml}$ of growth medium. The cell layer was scratched using a $2 \mathrm{~mm}$ wide tip to make a line-shaped wound and treated with fucoidan $(200 \mu \mathrm{g} / \mathrm{ml})$ alone, siPRNP transfection alone and both treatment for $48 \mathrm{~h}$ at $37^{\circ} \mathrm{C}$. The cells were allowed to migrate and images were acquired by capturing an inverted microscope (Eclipse TE300, Nikon, Tokyo, Japan).

Ethics statement. Experiments were performed on 8-week-old male BALB/CA-nu/nu mice (Biogenomics, Seoul, Korea; http:// www.orient.co.kr). All procedures were performed in accordance with the policies of the Institutional Animal Care and Use Committee of Soonchunhyang University, Seoul Hospital, Korea (IACUC2013-5). Throughout the experiment, all animals were monitored carefully for any distress, pain, or discomfort. All efforts were made to minimize suffering.

Tumor growth in mice. Up to five mice per cage were housed in Macrolon cages and supplied with woody bedding, shelters, and treadmills. The mice had ad libitum access to drinking water and standard chow. The environmental temperature was regulated at $22^{\circ} \mathrm{C}$, with a relative humidity of $\pm 45 \%$. The mice were subjected to a $12 / 12-\mathrm{h}$ day/night cycle under artificial lighting. The mice were allowed to acclimatize for at least 1 week before intraperitoneal injection of cancer cells. After intraperitoneal injection, body temperature was maintained at $36.5-37.5^{\circ} \mathrm{C}$ by placing animals on a heated table for $4 \mathrm{~h}$. At the end of the experiment, the mice were anesthetized with $5 \%$ isoflurane in $\mathrm{O}_{2} / \mathrm{N}_{2} \mathrm{O}$ and euthanized using carbon dioxide $\left(\mathrm{CO}_{2}\right)$ at 27 days after implantation. In vivo generation of tumors was accomplished by injection of $5 \times 10^{6}$ HT29 cells and si-PRNP transfected HT29 cells suspended in $50 \mu 1$ PBS into the back subcutaneously, respectively. Animal body weight and tumor size were measured and recorded. Tumor size was measured every 2 days in two perpendicular dimensions ( $a=$ length, $b=$ width) with a Vernier caliper, and the size recorded as a volume $\left(\mathrm{mm}^{3}\right)$ as calculated by: a $\times\left[(b / 2)^{2} \times 3.14\right]$. After the injected tumors reached a size of 8 to $10 \mathrm{~mm}^{3}$, the mice were intraperitoneally injected with normal saline (control; $\mathrm{n}=9$ ), or $5 \mathrm{mg} / \mathrm{kg}$ body weight fucoidan $(n=9)$ every 2 days for a total of nine administrations. A tumor growth curve was then constructed, and data were presented as the mean \pm SEM. After 27 days of tumor growth, the mice were euthanized and their tumors were excised and weighed. The tumor specimens were fixed in $4 \%$ formaldehyde, embedded in paraffin, and cut in $4-\mu \mathrm{m}$ sections for immunohistochemical analysis.

Propidium iodide (PI)/annexin $V$ flow cytometric analysis. Apoptosis of HT29 cells was assessed with a Cyflow Cube 8 (Partec, Münster, Germany) after staining the cells with annexin Vfluorescein isothiocyanate (FITC) and PI (De Novo Software, Los Angeles, CA, USA). Data analysis was performed using standard FSC Express (De Novo Software).

Western blot analysis. Total protein was extracted using RIPA Lysis Buffer (Thermo Scientific, Rockford, IL, USA). Cell lysates were separated by sodium dodecyl sulfate-polyacrylamide gel 
electrophoresis and proteins were transferred to polyvinylidene fluoride membranes (Millipore, Billerica, MA, USA). The membranes were blocked with 5\% skim milk and incubated with primary antibodies against phospho-CDK2, CDK4, cyclin D1, cyclin E, B-cell lymphoma 2 (BCL2), BCL-2-associated X protein (BAX), cleaved caspase-3, cleaved poly [ADP-ribose] polymerase 1 (PARP1), PrPC and $\beta$-actin (Santa Cruz Biotechnology, Dallas, TX, USA). After incubation of the membranes with peroxidaseconjugated secondary antibodies (Santa Cruz Biotechnology), bands were visualized using enhanced chemiluminescence reagents (Amersham Biosciences, Uppsala, Sweden).

Immunohistochemistry. Immunofluorescence staining was performed using primary antibodies against CD31, VEGF, PCNA and caspase-3 (Santa Cruz Biotechnology), as well as secondary antibodies conjugated with Alexa-488 (Life Technologies, Carlsbad, CA, USA). Nuclei were stained with 4',6-diamidino-2-phenylindole (Vector Laboratories, Burlingame, CA, USA). Immunostained slides were imaged by confocal microscopy (Olympus, Tokyo, Japan). The quantitative results are expressed the number of positive cells per field by ANOVA.

Statistical analyses. Quantitative results are expressed as the mean \pm SEM. All experimental results were analyzed by ANOVA. In some experiments, this was followed by a comparison of the treatment mean with the control using a Bonferroni-Dunn test. $p$ Values less than 0.05 were considered significant.

\section{Results}

Treatment with fucoidan inhibits proliferation and increases apoptosis signal pathways of HT29 cells. To assess the effect of fucoidan on the growth of HT29 cells, an MTT assay was performed to measure cell viability following the treatment of HT29 cells with fucoidan $(0,50,100$, and $200 \mu \mathrm{g} / \mathrm{ml})$ for $24 \mathrm{~h}$. Fucoidan treatment was found to reduce the viability of HT29 cells dose- and time-dependently (Figure 1A and B). In order to investigate the expression levels of cell cycleregulated proteins in HT29 cells treated with fucoidan, the levels of these proteins, including CDK2, cyclin E, CDK4, and cyclin D1, were confirmed by western blot analysis (Figure 1C-F). The levels of these proteins were significantly reduced after treatment with $200 \mu \mathrm{g} / \mathrm{ml}$ fucoidan in a timedependent manner, with the maximal effect being observed at $48 \mathrm{~h}$. These results demonstrate that fucoidan inhibits the proliferation of HT29 cells.

Next, in order to investigate the signaling pathways of fucoidan-induced apoptosis, apoptosis-associated proteins were assessed in vitro at different times after treatment with $200 \mu \mathrm{g} / \mathrm{ml}$ fucoidan. The anti-apoptotic protein BCL2 decreased and the pro-apoptotic proteins BAX, cleaved caspase-3, and cleaved PARP1 increased with fucoidan treatment (Figure 2A-D).

Fucoidan-induced inhibition of $\operatorname{PrP}^{c}$ expression along with si-PRNP treatment enhanced fucoidan-mediated effect of apoptosis and migration. Previous studies have suggested that $\mathrm{PrP}^{\mathrm{c}}$ plays important roles in cancer cell proliferation (20). The results of the western blots indicated that $\operatorname{PrP}^{\mathrm{c}}$ expression was reduced upon fucoidan treatment for 0 to $48 \mathrm{~h}$ (Figure 3A). The efficiency of $\mathrm{PrP}^{\mathrm{c}}$ silencing was verified by immunoblot analyses, which demonstrated a significant reduction of $\mathrm{PrP}^{\mathrm{c}}$ expression in si-PRNPtransfected cells (Figure 3B). Indeed, fucoidan significantly increased the percentage of the early and late apoptotic cells to $17.34 \%$ compared to the percentage in the control $(3.78 \%)$. In addition, si-PRNP-transfected cells significantly increased the early and late apoptotic cells to $10.07 \%$. The percentage of apoptotic cells was further increased in populations transfected with si-PRNP and treated with fucoidan (64.36\%) (Figure 3C and D).

Cancer cell migration plays a pivotal role in metastasis and tumor remodeling. Thus, we investigated the effect of si-PRNP on fucoidan-treated HT29 cell migration. A scratch wound-healing assay was performed following the treatment of HT29 cells with $200 \mu \mathrm{g} / \mathrm{ml}$ fucoidan for $48 \mathrm{~h}$ (Figure 4A and B). HT29 cell migration was significantly reduced in the fucoidan-treated group compared with the untreated group. The migration of cells decreased even more with si-PRNP transfection and treatment with fucoidan than with fucoidan alone.

si-PRNP enhanced fucoidan-induced reduction of proliferation in tumor tissue. In order to further confirm the ability of siPRNP and fucoidan to reduce proliferation in vivo, immunofluorescent staining was performed on tissue sections of tumors excised 27 days after implantation of HT29 cells or si-PRNP transfected HT29 cells, and the mice were treated with fucoidan. All treatments significantly reduced the number of PCNA-positive cells (Figure 5A and B) and significantly increased the number of caspase-3-positive apoptotic cells (Figure 5C and D) compared with the control. However, these effects were greatest for si-PRNP transfection combined with fucoidan treatment, suggesting that si-PRNP with fucoidan has a strong antitumor effect on the colon cancer model.

si-PRNP enhanced fucoidan-induced inhibition of colon tumor growth in vivo. The pronounced effect that si-PRNP transfection with fucoidan treatment produced on in vitro HT29 cell proliferation suggested that it may also suppress cancerous growth in vivo. In order to verify this hypothesis, we subcutaneously inoculated male Balb/C nude mice with si-PRNP and HT29 colon cancer cells. After implantation, visible tumors had developed at the injection sites ( 8 to 10 $\mathrm{mm}^{3}$ in size). As shown in Figure $6 \mathrm{~A}$ and $\mathrm{B}$, fucoidan reduced the tumor volume in mice but there was a significantly greater decrease in tumor volume in cells treated with both si-PRNP transfection and fucoidan than in cells treated with fucoidan alone. 
A

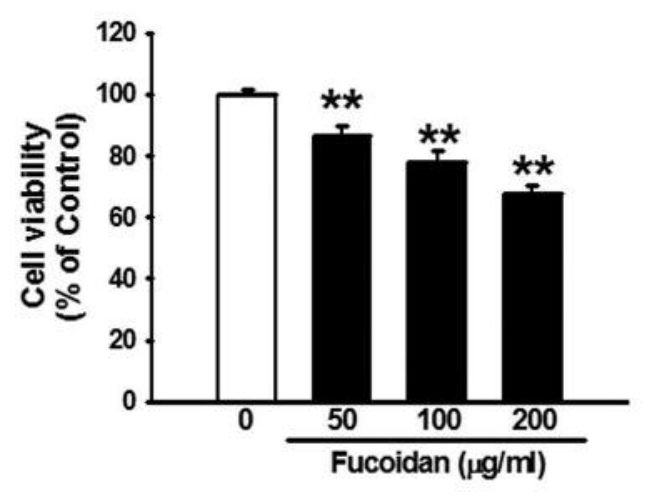

B

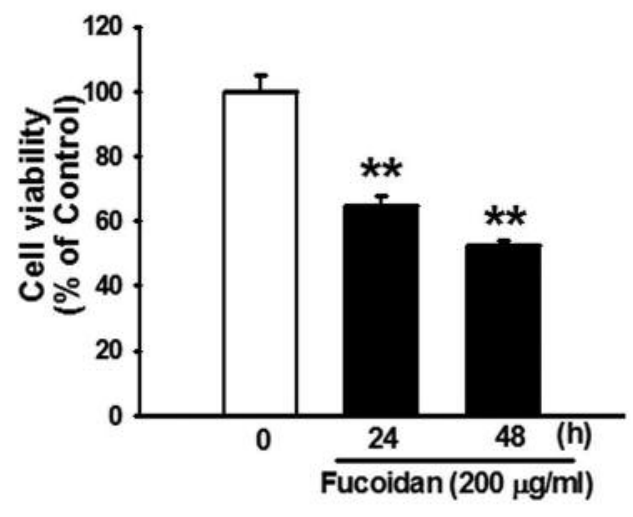

C
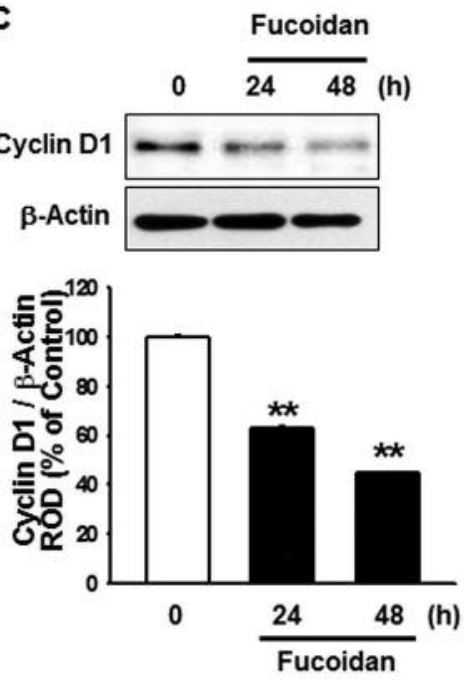

D
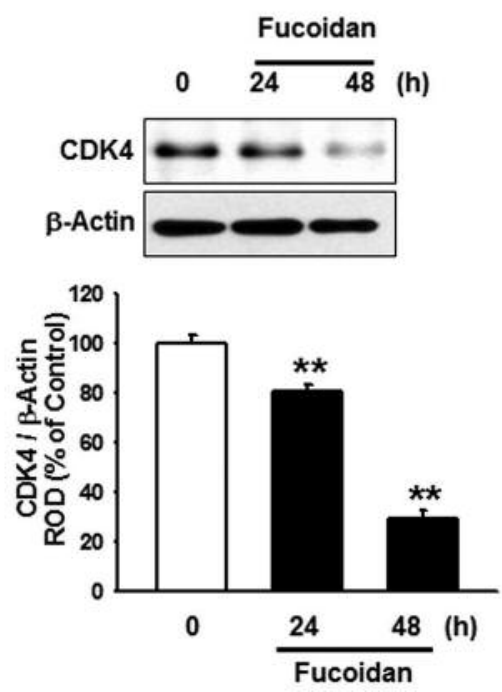

E
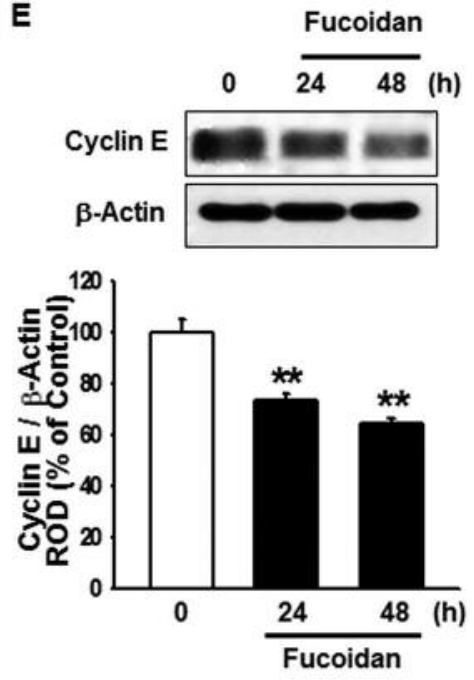

$\mathbf{F}$

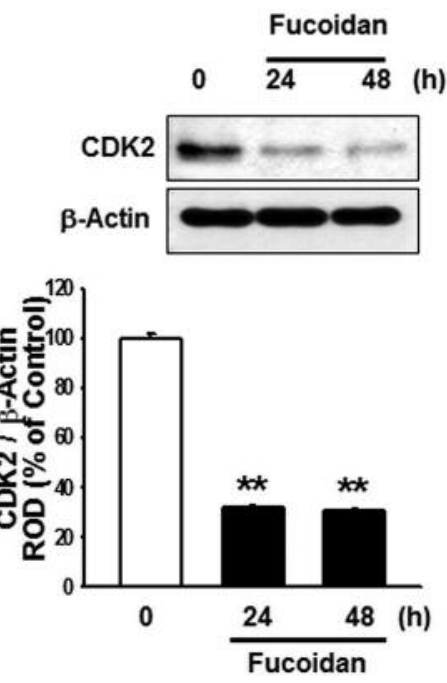

Figure 1. Fucoidan-mediated inhibition of cell viability and cell proliferation in HT29 colon cancer cells. A: HT29 colon cancer cells were treated with fucoidan $(0-200 \mu \mathrm{g} / \mathrm{ml})$ for $24 \mathrm{~h}$. B: HT29 colon cancer cells were treated with fucoidan $(200 \mu \mathrm{g} / \mathrm{ml})$ for different periods of time (0, 24 and 48 h). Cell viability was measured using a modified MTT assay. Values represent the means \pm SEM. $* * p<0.01$ vs. control. HT29 colon cancer cells were treated with fucoidan $(200 \mu \mathrm{g} / \mathrm{ml})$ for different periods of time $(0,24,48 \mathrm{~h})$ then the expression levels of cyclin D1 (C), cyclin-dependent kinase 4 $(C D K 4)(D)$, cyclin $E(E)$ and $C D K 2(F)$ were assessed using western blotting. The bar graph demonstrates the quantification of the expression levels of cell cycle-regulatory proteins as determined from densitometry relative to $\beta$-actin. Values represent means $\pm S E M . * * p<0.01 \mathrm{vs}$. control.

si-PRNP enhanced fucoidan-induced inhibition of angiogenesis in tumor tissue. To investigate the effect of siPRNP on fucoidan-induced angiogenesis in vivo, we analyzed the HT29 tumors by immunofluorescent staining to measure the expression of VEGF. Immunofluorescent staining of HT29 tumors showed a decrease in VEGF expression upon si-PRNP and fucoidan treatment (Figure 7A and $\mathrm{B}$ ). In addition, we evaluated CD31 expression as a measure of tumor vasculature in harvested HT29 tumors.
Figure 7C shows that expression of CD31 was reduced in the tumors excised from mice treated with si-PRNP-transfected HT29 cells and treated with fucoidan compared with those treated with fucoidan alone.

\section{Discussion}

In this study, we demonstrated that fucoidan, that is a natural product used for cancer therapy, interacts with the 
A
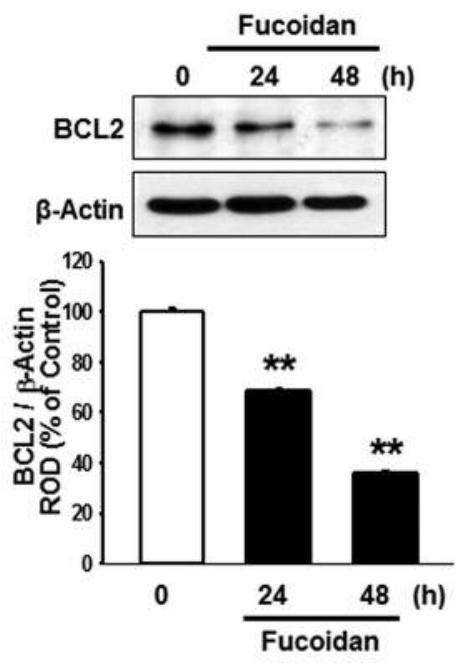

C
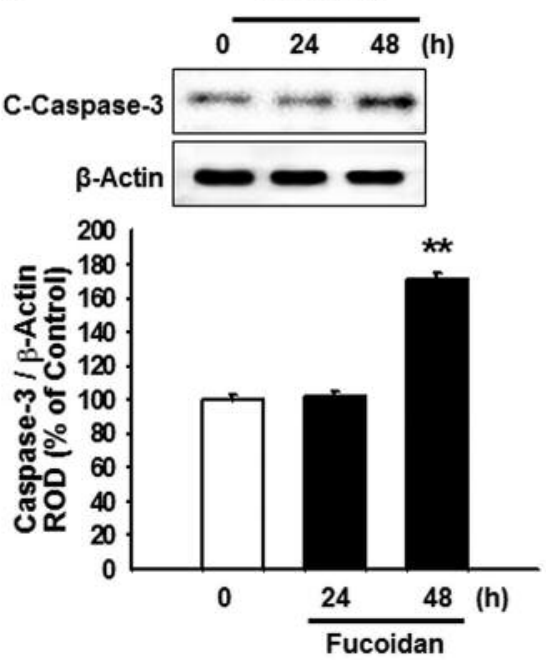

B
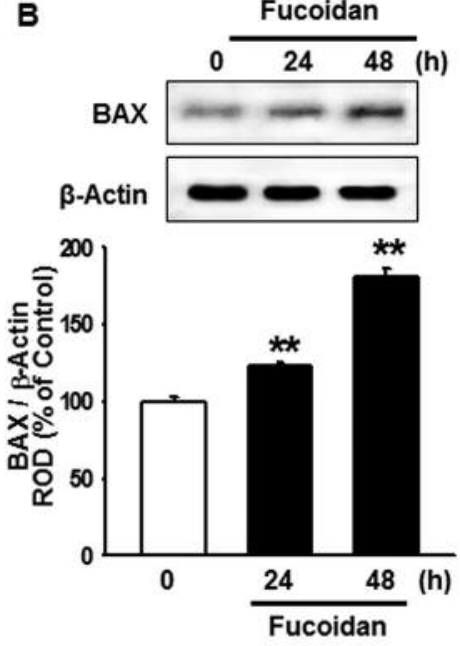

D
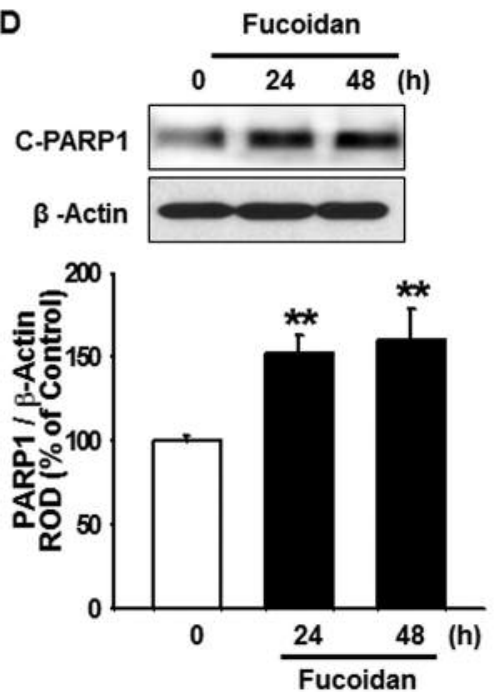

Figure 2. Effect of fucoidan on HT29 colon cancer cell apoptosis. HT29 colon cancer cells were treated with fucoidan (200 $\mu \mathrm{g} / \mathrm{ml})$ for different periods of time $(0,24$ and $48 \mathrm{~h})$ and the expression of B-cell lymphoma 2 (BCL2) (A), BCL-2-associated X protein (BAX) (B), cleaved caspase-3 $(C)$ and cleaved poly (ADP-ribose) polymerase 1 (PARP1) (D) was detected using western blot analysis. The bar graph demonstrates the quantification of the expression levels as determined from densitometry relative to $\beta$-actin. Values represent the means $\pm S E M . * * p<0.01$ vs. control.

suppression of $\operatorname{PrP}^{\mathrm{c}}$ to check the growth of CRC. Fucoidan affects CRC growth by inhibition of the cancer cell cycle and induction of cell death. In combination with fucoidan, silencing of $\operatorname{PrP}^{\mathrm{c}}$ leads to a greater reduction in cancer cell proliferation and cell motility, as well as tumor angiogenesis. Further study will be needed to explore the underlying molecular mechanisms of how silencing $\operatorname{PrP}^{\mathrm{c}}$ diminishes cancer cell growth and increases the susceptibility of cancer cells to fucoidan, as well as to understand how the degree to which $\operatorname{PrP}^{\mathrm{c}}$ protein levels are diminished correlates with fucoidan, eventually producing a synergic effect.

Fucoidan has been demonstrated to be a novel therapeutic agent for cancer treatment. Several studies have demonstrated that fucoidan induces cancer cell death through mitochondrial abnormalities, including increased production of mitochondrial reactive oxygen species (21), inhibits tumor angiogenesis via down-regulation of HIF1 and VEGF (14), down-regulates cell cycle-regulated kinase (22), and reduces 

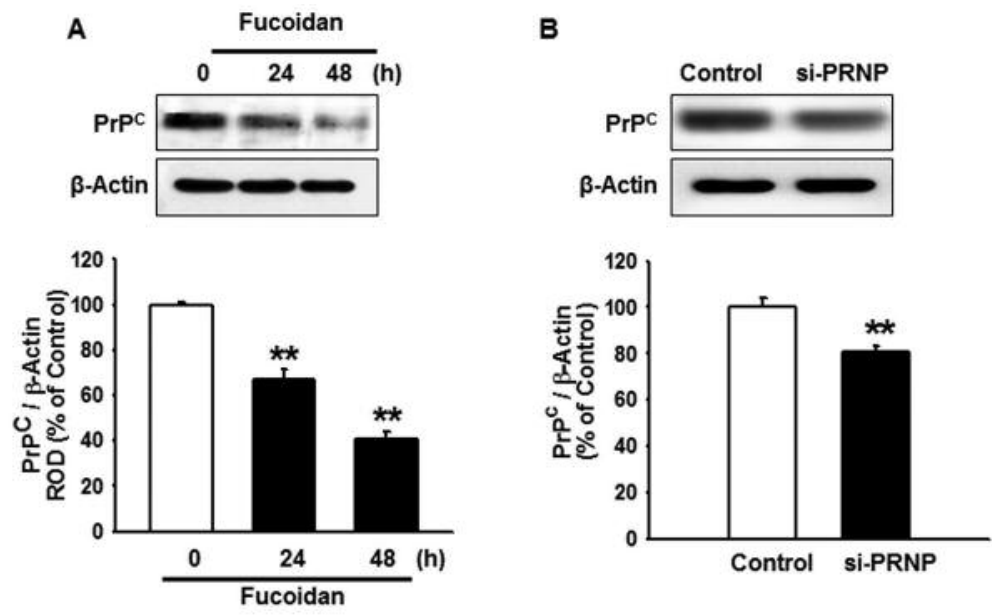

C

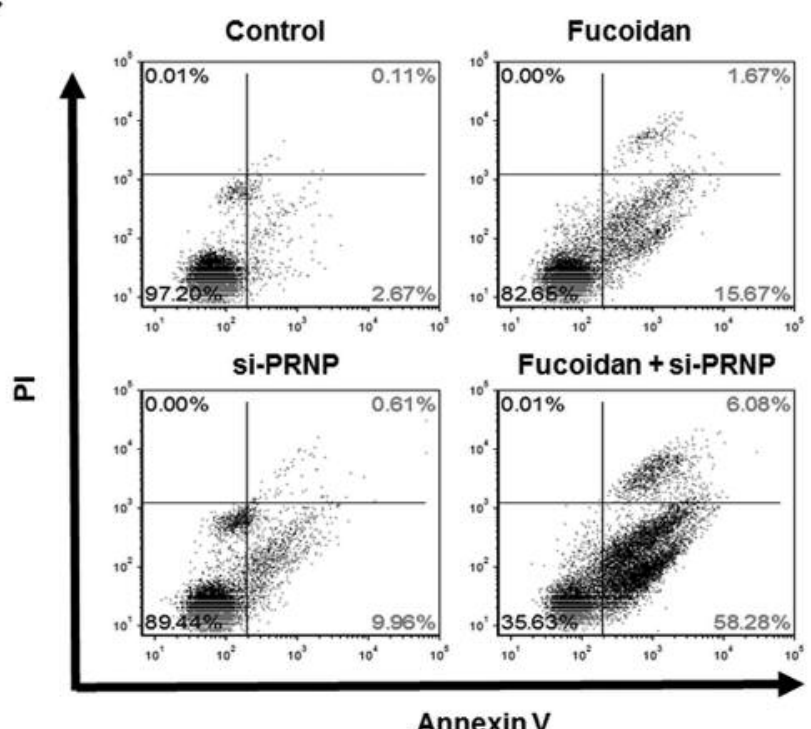

D

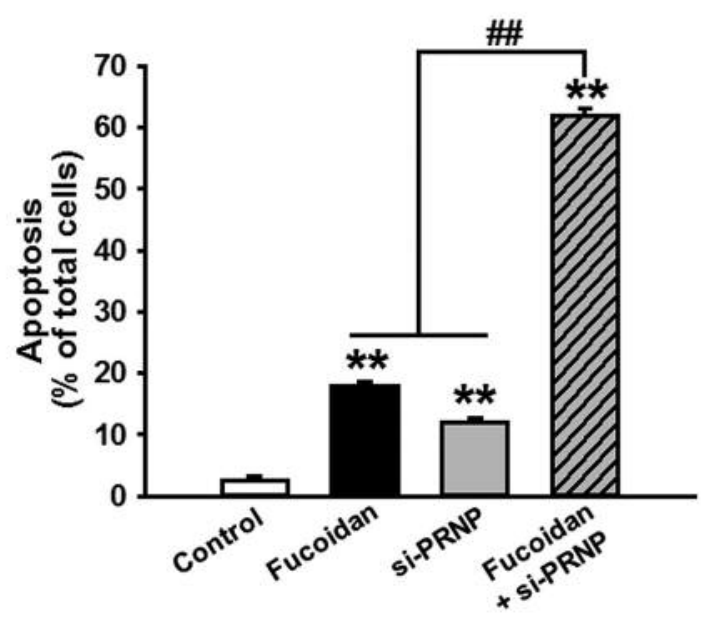

Figure 3. Fucoidan-induced inhibition of cellular prion protein $\left(\operatorname{Pr} P^{c}\right)$ expression and small-interfering RNA-PRNP (si-PRNP)-mediated enhancement of apoptosis. A: HT29 colon cancer cells were treated with fucoidan $(200 \mu \mathrm{g} / \mathrm{ml})$ for 24 and $48 \mathrm{~h}$. The activation of PrPc was then analyzed by western blot. B: HT29 colon cancer cells were transfected for $48 \mathrm{~h}$ with si-PRNP and then expression of PrPc was analyzed by western blot. C: HT29 colon cancer cells were transfected for $48 \mathrm{~h}$ with a si-PRNP and then incubated with or without fucoidan for 48 h. The apoptosis of cells was measured using propidium iodide (PI)/annexin V staining and flow cytometric analysis. PI/annexin V double-negative cells were considered live cells, PI-negative/annexin V-positive cells were considered early apoptotic cells, and PI/annexin V double-positive cells were considered late apoptotic cells. D: Standard quantification of PI/annexin V-positive apoptotic cells. Values represent the mean \pm SEM. $* * p<0.01 v s$. control, \#\#p<0.01 vs. fucoidan or si-PRNP alone.

colon cancer cell migration (23), suggesting that fucoidanaffected signaling contributes to the inhibition of cancer development. Although fucoidan is a natural product and an ingredient of dietary supplements responsible for anticancer effects (24), there is a possibility that fucoidan can also control CRC cell growth by modulating the cell cycle and apoptosis. After treatment with fucoidan, the expression of cell cycle-regulatory proteins such as cyclin D1 and E,
CDK2, and CDK4 was reduced, indicating the inhibition of cell proliferation. Moreover, proapoptotic BAX, cleaved caspase-3, and cleaved PARP1 increased while BCL2 decreased upon fucoidan treatment of HT29 cells, stimulating cell death. These results are supported by previous studies in which fucoidan inhibited proliferation of myeloid leukemia cell lines, mediated by activation of apoptotic pathways (21). Therefore, our results strongly suggest that fucoidan plays an 

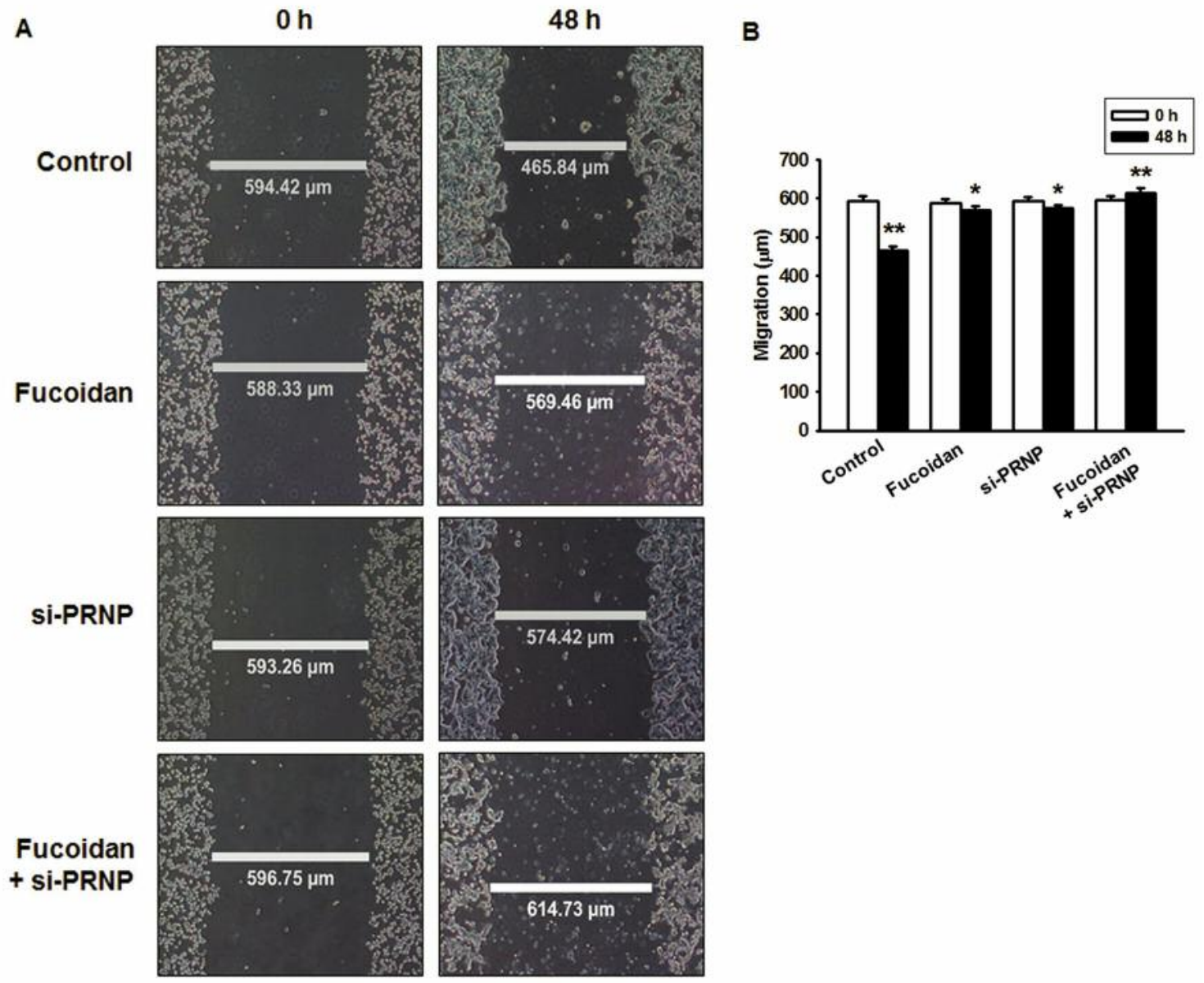

Figure 4. Application of small-interfering RNA-PRNP (si-PRNP) to fucoidan-induced HT29 colon cancer cells inhibits migration. A: HT29 colon cancer cells were placed on $60 \mathrm{~mm}$ culture plates and grown to $90 \%$ confluence. Cells were then scratched with a scraper and treated with fucoidan, or fucoidan with si-PRNP. Representative images of the effect of fucoidan on cell migration are shown. B: Standard quantification of migration distance. Values represent the means $\pm S E M . * p<0.05$ and ${ }^{* *} p<0.01$ vs. 0 h of each group.

important role in HT29 cell-cycle arrest and apoptosis. Further study is needed to ascertain whether alterations in cell-cycle arrest and apoptosis due to fucoidan may be involved in cancer cell death mechanisms displayed in fucoidan-treated CRC models.

It has been suggested that gain of $\mathrm{PrP}^{\mathrm{c}}$ function may contribute to cancer growth and metastasis in patients with $\operatorname{PrP}^{\mathrm{c}}$-associated cancer $(25,26)$. Previous studies on $\operatorname{PrP}^{\mathrm{c}}$ in cancer are generally consistent with the notion that $\operatorname{PrP}^{\mathrm{c}}$ expression increases resistance to cytotoxicity (27-31). One of the ways to eliminate this is via inhibition of glucose by various therapeutic drugs (32). There seems to be a reciprocal or synergic relationship between down-regulation of $\operatorname{PrP}^{\mathrm{c}}$ and cancer drugs. Down-regulation of $\operatorname{PrP}^{\mathrm{c}}$ due to treatments with targeted siRNA leads to a reduction in cancer cell survival (33). Consistent with previous findings in cancer models (33), we found that silencing $\operatorname{PrP}^{\mathrm{c}}$ slightly increased cancer cell death (Figure 3), while fucoidan treatment reduced endogenous $\operatorname{PrP}^{\mathrm{c}}$ levels. Thus, it is conceivable that silencing $\mathrm{PrP}^{\mathrm{c}}$ in cancer cells may be involved, leading to an increase in fucoidan-mediated cancer cell death and susceptibility to apoptosis. Thus, our study intended to test whether silencing $\operatorname{PrP}^{\mathrm{c}}$ was able to enhance fucoidan-induced inhibition of CRC cell proliferation in vitro and in vivo. Our results indicated that the combination of fucoidan and silencing of $\mathrm{PrP}^{\mathrm{c}}$ increased CRC cell death. These observations also suggest that fucoidan and $\operatorname{PrP}^{\mathrm{c}}$ have a reciprocal relationship, and that this relationship plays an important role in fucoidan-induced cell death. However, further mechanistic studies will be essential to establish whether the role of $\mathrm{PrP}^{\mathrm{c}}$ in response to fucoidan may be a consequence of cancer cell death by characterization of $\mathrm{PrP}^{\mathrm{c}}$ knock out mice with and without fucoidan treatment. 
A
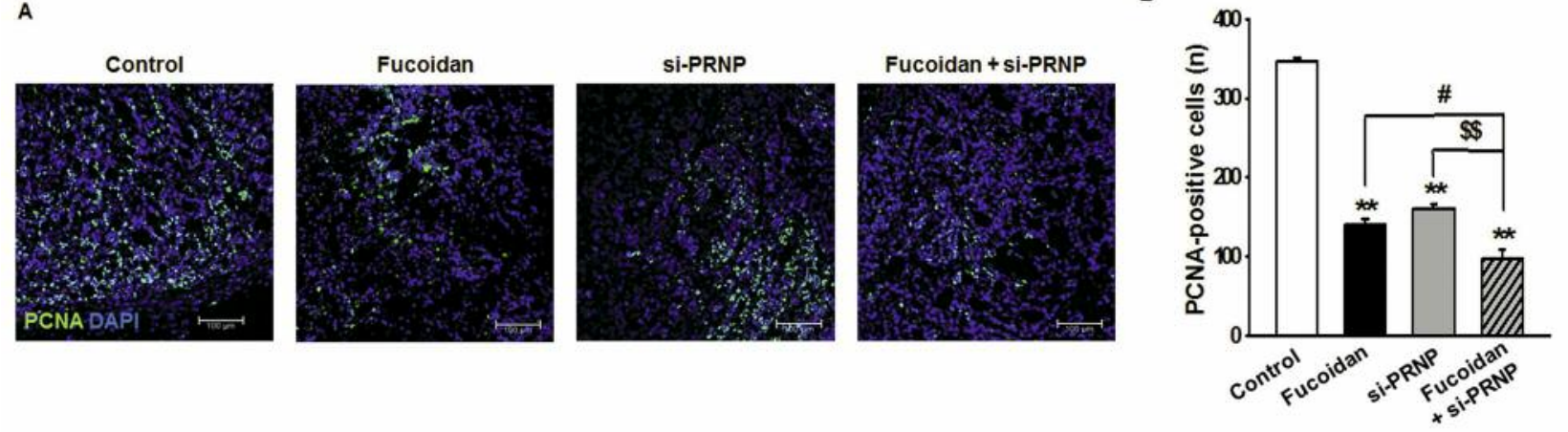

c

Control

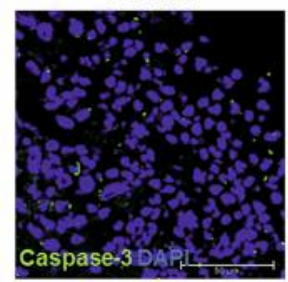

Fucoidan

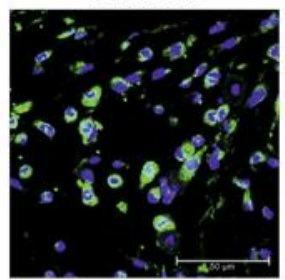

Si-PRNP

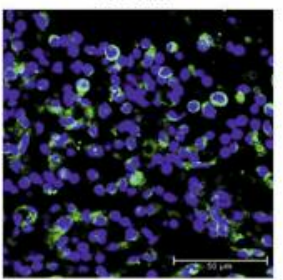

Fucoidan + si-PRNP

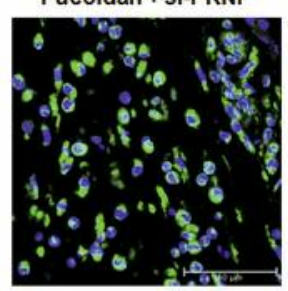

D

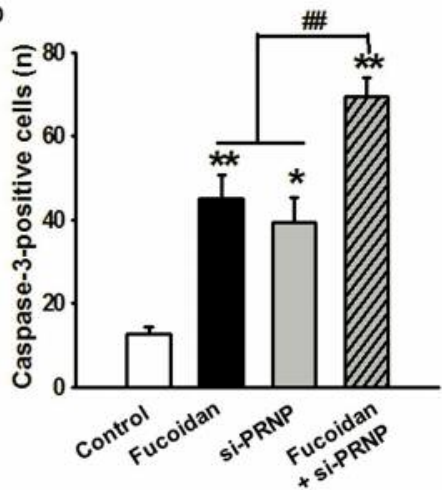

Figure 5. Effects of small-interfering RNA-PRNP (si-PRNP)-mediated fucoidan action on apoptosis in vivo. A: Proliferating cell nuclear antigen (PCNA) staining to detect tumor cell proliferation. Scale bar: $100 \mu \mathrm{m}$. B: Quantification of PCNA-positive cells number from tumors excised 27 days after implantation of HT29 cells and si-PRNP transfected HT29 cells in the mice treated with or without fucoidan. ${ }^{* *}<<0.05 \mathrm{vs}$. control. ${ }^{\#} p<0.05$ vs. fucoidan, ${ }^{\$ \$} p<0.01$ vs. si-PRNP $(n=9)$. C: Immunofluorescent staining to detect apoptosis was performed against cleaved caspase-3, an apoptosis marker (green) and DAPI (blue) for nuclear staining. Scale bar: $50 \mu \mathrm{m}$. D: Quantitative analysis of cleaved caspase-3/DAPI doublepositive cells number from tumors excised 27 days after implantation of HT29 cells and si-PRNP transfected HT29 cells in the mice treated with or without fucoidan. ${ }^{*} p<0.05$ vs. control, ${ }^{\#} p<0.01$ vs. fucoidan at $5 \mathrm{mg} / \mathrm{kg}(\mathrm{n}=9)$.

Taken together, the results from this study clearly established that fucoidan is effective as an anticancer drug for colorectal cancer. In addition, $\operatorname{PrP}^{\mathrm{c}}$ silencing in human colon cancer HT29 cells results in elevated responses to fucoidan treatment. These findings may have implications not only for understanding the role of $\mathrm{PrP}^{\mathrm{c}}$ in colon cancer biology, but also for elucidating the physiological function of $\operatorname{PrP}^{\mathrm{c}}$.

\section{Conflicts of Interest}

The Authors have no conflicts of interest to declare in regard to this study.

\section{Acknowledgements}

This study was supported by a National Research Foundation (NRF) grant funded by the Korean government (MEST) (2011-0009610) and by the Ministry of Education (2016R 1D 1A3B0100 7727). The funders had no role in study design, data collection or analysis, the decision to publish, or preparation of the article.

\section{References}

1 Bilan MI, Grachev AA, Ustuzhanina NE, Shashkov AS, Nifantiev NE and Usov AI: Structure of a fucoidan from the brown seaweed Fucus evanescens C.Ag. Carbohydr Res 337: 719-730, 2002.

2 Gideon TP and Rengasamy R: Toxicological evaluation of fucoidan from Cladosiphon okamuranus. J Med Food 11: 638642, 2008.

3 Li B, Lu F, Wei $X$ and Zhao R: Fucoidan: structure and bioactivity. Molecules 13: 1671-1695, 2008.

4 Thinh PD, Menshova RV, Ermakova SP, Anastyuk SD, Ly BM and Zvyagintseva TN: Structural characteristics and anticancer activity of fucoidan from the brown alga Sargassum mcclurei. Mar Drugs 11: 1456-1476, 2013.

5 Durig J, Bruhn T, Zurborn KH, Gutensohn K, Bruhn HD and Beress L: Anticoagulant fucoidan fractions from Fucus vesiculosus induce platelet activation in vitro. Thromb Res 85 : 479-491, 1997.

6 Senthilkumar K, Manivasagan P, Venkatesan J and Kim SK: Brown seaweed fucoidan: biological activity and apoptosis, 
A

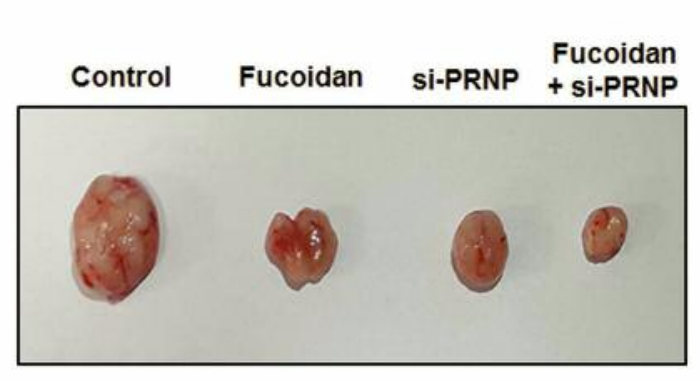

B

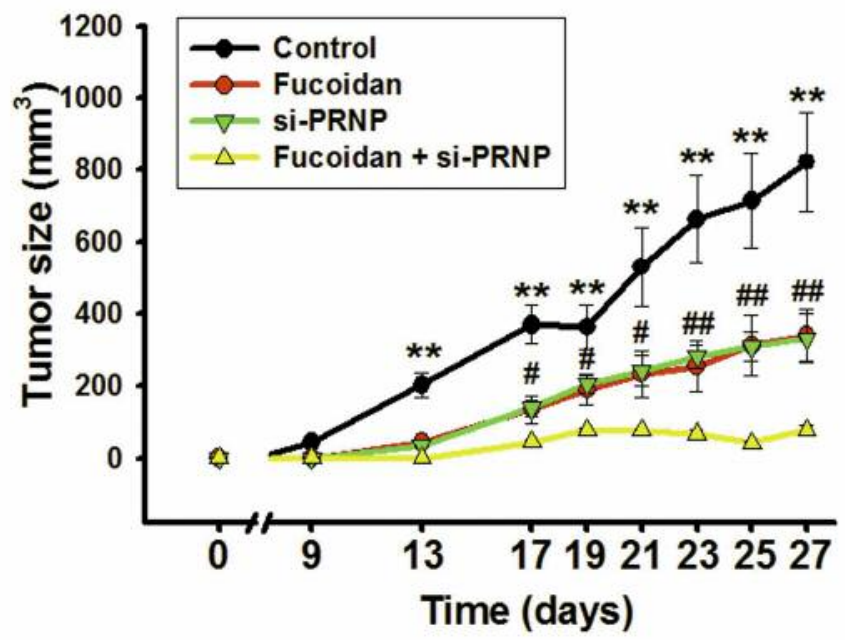

Figure 6. Antitumor effects of small-interfering RNA-PRNP (si-PRNP)-mediated fucoidan action on HT29 colon cancer in vivo. A: Representative photographs of tumor growth after treatment with fucoidan or si-PRNP alone and in combination. Mice were euthanized at 27 days after implantation of HT29 cells or si-PRNP transfected HT29 cells, and treatment with or without fucoidan B: The bar graph shows quantitative analysis of tumor size at 27 days after treatment. ${ }^{* *} p<0.05$ vs. fucoidan or si-PRNP alone, ${ }^{\#} p<0.05$ vs. fucoidan with si-PRNP, ${ }^{\#} p<0.01$ vs. fucoidan with si-PRNP ( $\left.n=9\right)$.

A

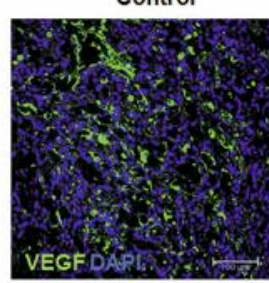

B

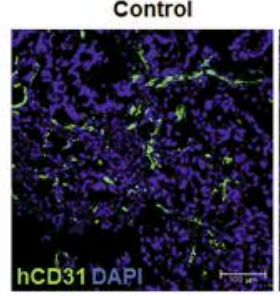

Fucoidan

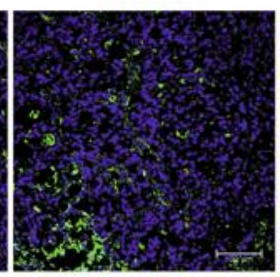

Fucoidan

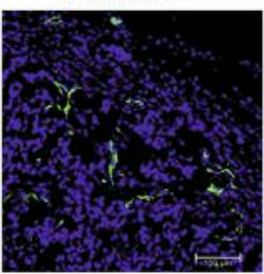

SI-PRNP

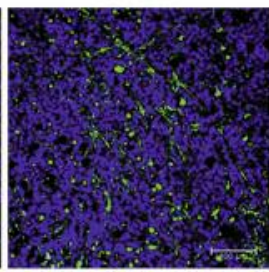

Si-PRNP

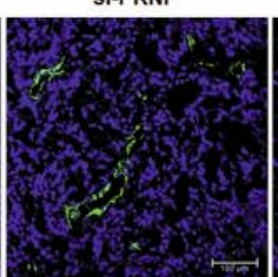

Fucoidan + si-PRNP

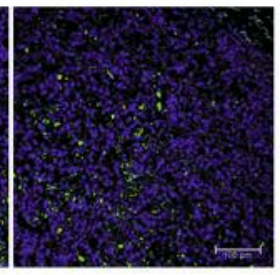

Fucoidan + si-PRNP

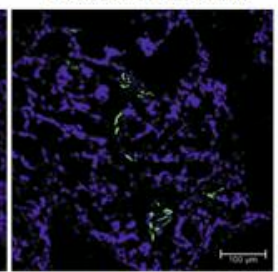

C

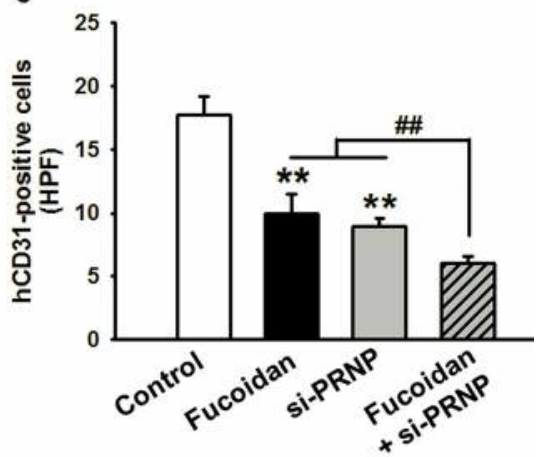

Figure 7. Small-interfering RNA-PRNP (si-PRNP)-mediated fucoidan-induced inhibition of tumor angiogenesis in vivo. A: Representative photographs of the tumor sections as examined by immunohistochemical staining for vascular endothelial growth factor (VEGF). Scale bar: $100 \mu \mathrm{m}$. B: Representative photographs of the tumor sections examined by immunohistochemical staining for human cluster of differentiation 31 (hCD31) in order to examine tumor vasculature. Scale bar: $100 \mu \mathrm{m}$. C: Standard quantification of human CD31-positive cells shown as the number of human CD31-positive cells in tumor per high-power field (HPF) (n=9). Values represent the mean \pm SEM. ${ }^{* *} p<0.01 \mathrm{vs}$. control, \#\#p<0.01 vs. fucoidan or si-PRNP alone.

growth signaling mechanism in cancer. Int J Biol Macromol 60: 366-374, 2013.

7 Lee H, Kim JS and Kim E: Fucoidan from seaweed Fucus vesiculosus inhibits migration and invasion of human lung cancer cell via PI3K-AKT-mTOR pathways. PLoS One 7: e50624, 2012.

8 Prokofjeva MM, Imbs TI, Shevchenko NM, Spirin PV, Horn S, Fehse B, Zvyagintseva TN and Prassolov VS: Fucoidans as potential inhibitors of HIV-1. Mar Drugs 11: 3000-3014, 2013.
9 Boo HJ, Hong JY, Kim SC, Kang JI, Kim MK, Kim EJ, Hyun JW, Koh YS, Yoo ES, Kwon JM and Kang HK: The anticancer effect of fucoidan in PC-3 prostate cancer cells. Mar Drugs 11: 2982-2999, 2013.

10 Zhang Z, Teruya K, Yoshida T, Eto H and Shirahata S: Fucoidan extract enhances the anticancer activity of chemotherapeutic agents in MDA-MB-231 and MCF-7 breast cancer cells. Mar Drugs 11: 81-98, 2013. 
11 Nagamine T, Hayakawa K, Kusakabe T, Takada H, Nakazato K, Hisanaga $\mathrm{E}$ and Iha M: Inhibitory effect of fucoidan on Huh7 hepatoma cells through down-regulation of CXCL12. Nutr Cancer 61: 340-347, 2009.

12 Park HS, Hwang HJ, Kim GY, Cha HJ, Kim WJ, Kim ND, Yoo YH and Choi YH: Induction of apoptosis by fucoidan in human leukemia U937 cells through activation of p38 MAPK and modulation of BCL2 family. Mar Drugs 11: 2347-2364, 2013.

13 Vishchuk OS, Sun H, Wang Z, Ermakova SP, Xiao J, Lu T, Xue P, Zvyagintseva TN, Xiong H, Shao C, Yan W, Duan Q and Zhu F: PDZ-binding kinase/T-LAK cell-originated protein kinase is a target of the fucoidan from brown alga Fucus evanescens in the prevention of EGF-induced neoplastic cell transformation and colon cancer growth. Oncotarget 2016.

14 Chen MC, Hsu WL, Hwang PA and Chou TC: Low molecular weight fucoidan inhibits tumor angiogenesis through downregulation of HIF-1/VEGF signaling under hypoxia. Mar Drugs 13: 4436-4451, 2015.

15 Jemal A, Murray T, Ward E, Samuels A, Tiwari RC, Ghafoor A, Feuer EJ and Thun MJ: Cancer statistics, 2005. CA Cancer J Clin 55: 10-30, 2005.

16 Thomas HJ: Familial colorectal cancer. BMJ 307: 277-278, 1993.

17 Park JY, Jeong JK, Lee JH, Moon JH, Kim SW, Lee YJ and Park $\mathrm{SY}$ : Induction of cellular prion protein $\left(\mathrm{PrP}^{\mathrm{c}}\right)$ under hypoxia inhibits apoptosis caused by TRAIL treatment. Oncotarget 6 : 5342-5353, 2015

18 Bueler H, Aguzzi A, Sailer A, Greiner RA, Autenried P, Aguet $\mathrm{M}$ and Weissmann C: Mice devoid of PrP are resistant to scrapie. Cell 73: 1339-1347, 1993.

19 Klein MA and Aguzzi A: The neuroimmune interface in prion diseases. News Physiol Sci 15: 250-255, 2000.

20 Mehrpour M and Codogno P: Prion protein: From physiology to cancer biology. Cancer Lett 290: 1-23, 2010.

21 Wei C, Xiao Q, Kuang X, Zhang T, Yang Z and Wang L: Fucoidan inhibits proliferation of the SKM-1 acute myeloid leukaemia cell line via the activation of apoptotic pathways and production of reactive oxygen species. Mol Med Rep 12: 6649$6655,2015$.

22 Yoshimoto M, Higaki K, Nanba E and Ikeguchi M: Antiproliferation activity of fucoidan in MKN45 gastric cancer cells and downregulation of phosphorylated ASK1, a cell cycleregulated kinase. Yonago Acta Med 58: 1-7, 2015.

23 Han YS, Lee JH and Lee SH: Fucoidan inhibits the migration and proliferation of HT-29 human colon cancer cells via the phosphoinositide-3 kinase/AKT/mechanistic target of rapamycin pathways. Mol Med Rep 12: 3446-3452, 2015.

24 Han YS, Lee JH and Lee SH: Antitumor effects of fucoidan on human colon cancer cells via activation of AKT signaling. Biomol Ther 23: 225-232, 2015.
25 Cheng Y, Tao L, Xu J, Li Q, Yu J, Jin Y, Chen Q, Xu Z, Zou Q and Liu X: CD44/cellular prion protein interact in multidrugresistant breast cancer cells and correlate with responses to neoadjuvant chemotherapy in breast cancer patients. Mol Carcinog 53: 686-697, 2014.

26 Du L, Rao G, Wang H, Li B, Tian W, Cui J, He L, Laffin B, Tian X, Hao C, Liu H, Sun X, Zhu Y, Tang DG, Mehrpour M, Lu Y and Chen Q: CD44-positive cancer stem cells expressing cellular prion protein contribute to metastatic capacity in colorectal cancer. Cancer Res 73: 2682-2694, 2013.

27 Meslin F, Conforti R, Mazouni C, Morel N, Tomasic G, Drusch F, Yacoub M, Sabourin JC, Grassi J, Delaloge S, Mathieu MC, Chouaib S andre F and Mehrpour M: Efficacy of adjuvant chemotherapy according to Prion protein expression in patients with estrogen receptor-negative breast cancer. Ann Oncol 18: 1793-1798, 2007.

28 Li QQ, Cao XX, Xu JD, Chen Q, Wang WJ, Tang F, Chen ZQ, Liu XP and Xu ZD: The role of P-glycoprotein/cellular prion protein interaction in multidrug-resistant breast cancer cells treated with paclitaxel. Cell Mol Life Sci 66: 504-515, 2009.

29 Diarra-Mehrpour M, Arrabal S, Jalil A, Pinson X, Gaudin C, Pietu G, Pitaval A, Ripoche H, Eloit M, Dormont D and Chouaib S: Prion protein prevents human breast carcinoma cell line from tumor necrosis factor alpha-induced cell death. Cancer Res 64: 719-727, 2004

30 Meslin F, Hamai A, Gao P, Jalil A, Cahuzac N, Chouaib S and Mehrpour M: Silencing of prion protein sensitizes breast adriamycin-resistant carcinoma cells to TRAIL-mediated cell death. Cancer Res 67: 10910-10919, 2007.

31 Roucou X, Giannopoulos PN, Zhang Y, Jodoin J, Goodyer CG and LeBlanc A: Cellular prion protein inhibits proapoptotic BAX conformational change in human neurons and in breast carcinoma MCF-7 cells. Cell Death Differ 12: 783-795, 2005.

$32 \mathrm{Li}$ QQ, Sun YP, Ruan CP, Xu XY, Ge JH, He J, Xu ZD, Wang $\mathrm{Q}$ and Gao WC: Cellular prion protein promotes glucose uptake through the FYN-HIF-2alpha-GLUT1 pathway to support colorectal cancer cell survival. Cancer Sci 102: 400-406, 2011.

33 Li C, Yu S, Nakamura F, Yin S, Xu J, Petrolla AA, Singh N, Tartakoff A, Abbott DW, Xin W and Sy MS: Binding of proprion to filamin A disrupts cytoskeleton and correlates with poor prognosis in pancreatic cancer. J Clin Invest 119: 2725-2736, 2009. 